\title{
Role of Dendritic Cells in Inflammation and Loss of Tolerance in the Elderly
}

\author{
Anshu Agrawal*, Sudhanshu Agrawal and Sudhir Gupta* \\ Division of Basic and Clinical Immunology, Department of Medicine, University of California, Irvine, Irvine, CA, United States
}

OPEN ACCESS

Edited by:

Peter Katsikis,

Erasmus University Rotterdam,

Netherlands

Reviewed by:

Wolfgang Kastenmüller,

University of Bonn, Germany

Yvonne Mueller,

Erasmus Medical Center

Netherlands

*Correspondence:

Anshu Agrawal

aagrawa/@uci.edu;

Sudhir Gupta

sgupta@uci.edu

Specialty section:

This article was submitted to Immunological Memory,

a section of the journal

Frontiers in Immunology

Received: 11 April 2017

Accepted: 13 July 2017

Published: 26 July 2017

Citation:

Agrawal A, Agrawal S and Gupta S (2017) Role of Dendritic Cells

in Inflammation and Loss of

Tolerance in the Elderly.

Front. Immunol. 8:896.

doi: 10.3389/fimmu.2017.00896
Dendritic cells (DCs) play an important role in advancing age-associated progressive decline in adaptive immune responses, loss of tolerance, and development of chronic inflammation. In aged humans, DCs secrete increased levels of pro-inflammatory cytokines and decreased levels of anti-inflammatory and immune-regulatory cytokines. This may contribute to both chronic inflammation and loss of tolerance in aging. Aged DCs also display increased immune response against self-antigens contributing further to both inflammation and loss of tolerance. The secretion of innate protective cytokines such as type I and III interferons is decreased, and the function of DCs in airway remodeling and inflammation in aged is also compromised. Furthermore, the capacity of DCs to prime $T$ cell responses also seems to be affected. Collectively, these changes in DC functions contribute to the immune dysfunction and inflammation in the elderly. This review only focuses on age-associated changes in DC function in humans.

Keywords: dendritic cells, inflammation, tolerance, aging, mucosa

\section{INTRODUCTION}

Medical and technological advances have significantly enhanced the life expectancy of the human population (1-3). As a result, age expectancy has increased but is accompanied by a substantial increase in age-related diseases including cardiovascular, neurodegenerative disorders, infections, autoimmunity, diabetes, and cancers. Age-related immune dysfunction contributes to the increased incidence of these diseases due to impaired surveillance, repair, and regulation $(4,5)$. Advanced age affects the functions of both the innate and the adaptive arms of the immune system. Changes in adaptive immune $\mathrm{T}$ and $\mathrm{B}$ cells are more apparent as there is decline in cell numbers as well as functions (6). In contrast, functions of innate immune cells, such as dendritic cells (DCs), macrophages do not display major numerical or phenotypic changes; however, significant changes in regulation of the immune responses by these cells exist (7). DCs are well established as the most effective of the antigen-presenting cells (APCs) (8). They express high levels of the molecules that are required for antigen presentation such as the MHC II, CD80, and CD86 on activation $(9,10)$. DCs are thus highly effective in initiating an immune response (11). DCs are distributed throughout the body, including the mucosal tissues, where they are found below the epithelial cell barrier. DCs present at the mucosal sites, and in tissues, survey for external and internal danger signals using an array of pattern recognition receptors such as the toll-like receptor (TLRs), C-type lectin receptors, NODlike receptors (NLRs), and others (12). These receptors can sense not only external infectious and environmental antigens but are also capable of responding to internal danger signals and molecules generated during tissue injury or malfunctioning of any of the other processes in the body (13). 
Following uptake of antigens via the PRRs, DCs are activated and migrate to the lymph nodes to present antigens to the T cells, and initiate an adaptive immune response. In contrast, presentation of antigens, particularly self-antigens to $\mathrm{T}$ cells by unactivated DC prevents T cell activation and induces tolerance (14). DCs, thus play, a dual role that of generating immunity against danger signals and preventing immunity against self. Since increased susceptibility to infections as well as increased reactivity to self is a characteristic of aging, aberrant DC function can play a major role in age-related disorders. This review therefore focuses on the changes in human DC functions in the aged population.

\section{NUMBERS AND PHENOTYPE}

Dendritic cells can be divided into two major subclasses (1) plasmacytoid DCs (pDCs), which are of lymphoid origin and express B plasma cell markers; (2) myeloid DCs (mDCs) that are derived from myeloid progenitors (15). Hematopoiesis in aging is characterized by decrease in lymphoid cells with skewing toward the myeloid lineages $(16,17)$. In keeping with this, a decrease in pDC numbers in circulation has been observed in the aged population (18-20). Myeloid DC numbers have been reported to be largely unchanged in circulation (18, 20-22). Recent data from DC field have led to the further division of myeloid DC into several subsets (15). However, only two of these are present in the circulation, the $\mathrm{CD} 1 \mathrm{c}^{+}$and the $\mathrm{CD} 141^{+} \mathrm{mDC}$ subsets. We have observed a decrease in the $\mathrm{CD} 141^{+} \mathrm{mDC}$ subset in the circulation of the aged subjects; however, the number of $\mathrm{CD} 1 \mathrm{c}^{+} \mathrm{mDC}$ was not affected with age (23). Monocyte-derived DCs (MoDCs) represent a third subset of DCs. MoDCs have similar functions as myeloid DCs in circulation though recent genomic studies suggest that these two populations are significantly different at the transcriptome level (24). The MoDCs numbers are also stable with age (21). The phenotype of the DCs is also reported to be largely unchanged though most of the data are from MoDCs (21, 25-27), and very few studies have examined the phenotype of $\mathrm{pDCs}$ and $\mathrm{mDCs}$ $(18,20,22)$.

Information regarding the age-associated changes in tissue DCs is scarce due to the difficulty in obtaining human samples. Nevertheless, a very recent and comprehensive study by Granot et al. (28) has examined the $\mathrm{CD} 1 \mathrm{c}^{+}$and $\mathrm{CD} 141^{+} \mathrm{mDC}$ distribution, activation, and migration in various organs including the lung and the intestine and associated lymph nodes. The samples were from 78 organ donors of various ethnicities with ages ranging from infants to 93-year-old adults. The authors did not observe significant changes in DC subset frequencies throughout life in most tissues. They did observe a trend toward increased maturation of DCs particularly $\mathrm{CD} 1 \mathrm{c}^{+} \mathrm{DC}$ subset in the lung, mesenteric, and inguinal lymph nodes indicating increased activation and migration of DCs with age.

\section{PATHOGEN SENSING AND RESPONSE OF DCs}

A hallmark of advancing age is an increased susceptibility to acute viral and bacterial infections. These infections are often more severe and prolonged, with a higher mortality rate among older adults (29). One of the primary functions of DCs as a part of the innate immune system is to sense and respond to external pathogenic stimuli via PRRs such as TLRs. The function of TLRs in aged subjects has been reported to be defective in both $\mathrm{mDC}$ and pDC subsets (18).

Among the DC subsets, pDCs play a major role in controlling viral infections via secretion of large amounts of type I interferons early in the immune response (30). A decrease in IFN secretion by pDCs from elderly in response to TLR7 and TLR9 ligands as well as to different viruses including influenza has been reported $(18,20,31,32)$. The data on the expression of TLR7 in pDC from aged subjects are rather conflicting; both decreased and normal expression has been reported (18); expression of TLR9 in pDC in elderly is comparable to young subjects. Impaired functions of pDCs are considered a major factor in increased susceptibility of elderly to viral infections.

In addition to $\mathrm{pDCs}, \mathrm{mDCs}$ also play a major role in defense against microbes. mDCs in circulation express a wide array of PRRs including TLRs. Few studies have examined the expression and functions of TLRs in mDC in humans. Panda et al. (18) have performed an extensive analysis of the intracellular cytokine secretion by $\mathrm{mDCs}$ in response to multiple TLR ligands including TLR1/2, TLR2/6, TLR3, TLR4, TLR5, and TLR8. They observed a significant decrease in the production of TNF- $\alpha$, IL- 6 , and IL-12p40 against almost all ligands tested. The decrease was consistent and was there even when the subjects were retested after an interval of 2 years. The decrease was attributed in part to reduced expression of TLR1, TLR3, and TLR8. TLR2 and TLR4 expression was reported to be unaltered. Della Bella et al. (33) have also reported a decreased IL-12 production by DCs from peripheral blood mononuclear cells from aged subjects in response to TLR4 ligand as compared to young individuals. There are no studies with purified mDCs probably due to very small number of circulating mDCs.

In contrast to $\mathrm{mDCs}$ in circulation, we have observed that MoDCs display increased secretion of pro-inflammatory cytokines TNF- $\alpha$, CXCL-10, and IL- 6 in response to TLR4 ligand, LPS (21). We also observed similar increase in these mediators in response to Chlamydophila pneumoniae (34). This increase was attributed to decrease in signaling via the PI3kinase/Akt pathway, which functions as a negative regulator of TLR signaling. Increased PTEN expression in DCs from aged subjects was found to be responsible for the deficient function of AKT (21). Most remarkably, we also observed a significant age-associated decrease in the secretion of the anti-inflammatory cytokine, IL-10, which is required to regulate inflammation. This defect in IL-10 secretion by DCs from aged subjects was a consequence of an inherent defect in DCs as addition of IL-10-inducing agents such as lithium chloride was unable to restore the production of IL-10 in DCs from aged subjects (35). This decrease in IL-10 production may also contribute to loss of tolerance in aging. In addition to impaired IL-10 production, DCs from aged subjects also displayed a defect in the production of type I and III interferons in response to both influenza and Chlamydophila $(34,36)$. The decrease in type I IFN production in older donors was also observed in MoDCs infected with West Nile virus (32). Interferons, both type I and III, 
are essential for blocking viral replication and preventing spread of infection $(37,38)$. In addition, the interferons also act on various cells to induce an antiviral state. Though the actions of both interferons are similar, type III interferons play a more important role in protection against infections of the mucosal surfaces. This is because the receptors for type I interferons are present on nearly all cells of the body, while type III display a more restricted pattern of expression with the receptors being present mainly on mucosal tissues (38). Type III IFNs thus contribute to the control of viral infections in epithelial cells of both respiratory and gastrointestinal tracts. Together, MoDCs from aged subjects display a selective deficiency in anti-inflammatory and protective cytokines accompanied with an increase in pro-inflammatory cytokines and chemokines (Figure 1).

\section{DCs AND IMPAIRED VACCINE RESPONSES IN THE ELDERLY}

Vaccine responses in the elderly are also compromised $(39,40)$. Reduced responses to influenza vaccines are well documented
(40). Elderly display deficiency in mounting efficient immune response to new antigens or vaccines, but their capacity to generate recall responses to previously primed antigens is relatively better preserved (41). The underlying mechanisms are not well understood; in particular, the possible contribution of ageassociated DC dysfunction has not been examined in humans. Successful response to vaccines requires presentation of the antigens by DCs as well as costimulation (42). DCs are important not only for the initiation of $\mathrm{T}$ cell responses but also for the generation of efficient effector and memory responses (43-47). Reduced phagocytosis as well as impaired migration of DCs from aged subjects may be one of the factors for the decreased vaccine responses (21). Furthermore, DCs also need to upregulate class I and II MHC molecules as well as costimulatory molecules, CD40, CD80 as well as CD86 for efficient antigen presentation. The response of human monocyte-derived DCs to TLR ligands indicates that the capacity of DCs from elderly to upregulate MHC and costimulatory molecules is not impaired $(21,25,26)$. This is in contrast to murine DCs where reduced expression of CD80, CD86, and MHC II has been observed in DCs before and after infection (48-50). The discrepancy could be due to

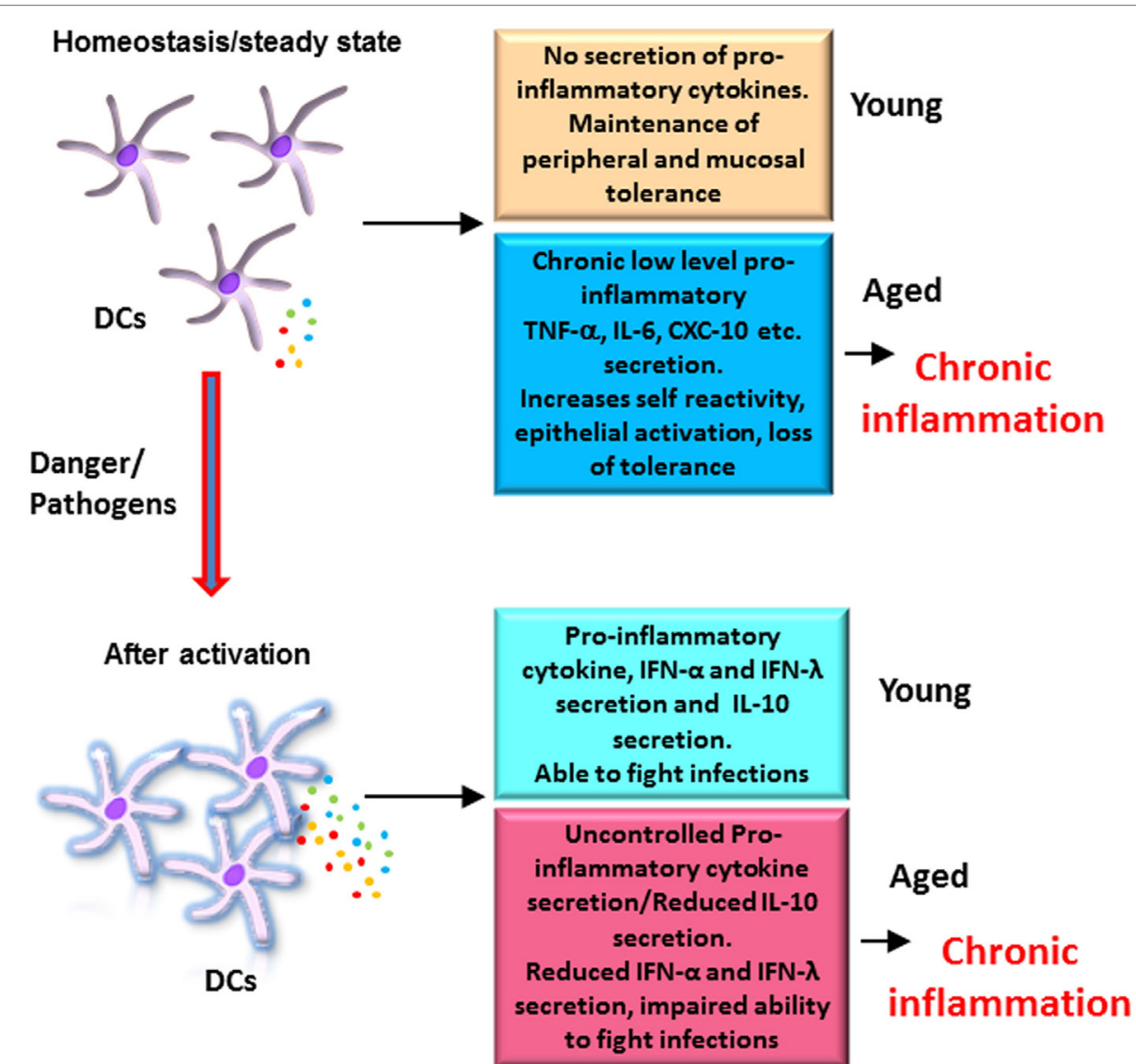

FIGURE 1 | Altered functions of dendritic cells (DCs) from elderly contribute to chronic inflammation: DCs from elderly display an enhanced basal level of activation, which increases their reactivity to self-antigens, affects the function of epithelial barrier, and results in erosion of peripheral and mucosal tolerance at homeostasis. After activation with pathogens, DCs from elderly secrete enhanced levels of pro-inflammatory cytokines, which are not regulated as the secretion of antiinflammatory cytokine IL-10 is impaired. This also contributes to inflammation. In addition, secretion of protective cytokines such as the IFN- $\alpha$ and IFN- $\lambda$ is also decreased resulting in a decrease in the ability of elderly to fight infections. Figure depicts the differences in the response of DCs from aged and young subjects at homeostasis and after activation. 
difference in species. However, most of the information is derived from MoDCs, and the expression of costimulatory molecules on human DC subsets in circulation or in tissues after stimulation/ infection has not been investigated. It is possible that these DCs may behave differently compared to MoDCs. MoDCs from young and aged subjects have also been reported to have similar stimulatory capacity to induce proliferation of $\mathrm{T}$ cell lines developed in long-term cultures (26). However, during respiratory syncytial virus infection, decreased IFN- $\gamma$-producing cells were observed in response to MoDCs from old individuals (51). We have observed increased proliferation as well as IFN- $\gamma$ secretion by T cells primed with MoDC from older subjects in the absence of stimulation supporting the enhanced activated state of DCs in the elderly (34). However, MoDCs from aged subjects were not as efficient as MoDCs from young subjects in enhancing the T cell proliferation and IFN- $\gamma$ secretion after stimulation (34). In another study also, elderly adults displayed a reduced ability to prime antigen-specific $\mathrm{CD}^{+} \mathrm{T}$ cells (52). Furthermore, the expression of perforin and granzyme $\mathrm{B}$ was also reduced in the primed $\mathrm{CD}^{+} \mathrm{T}$ cells. Reduced $\mathrm{T}$ cell proliferation has also been reported in another study where TLR agonist-stimulated PBMCs (minus CD3 T cells) from older subjects' induced lower proliferation of allogeneic adult $\mathrm{T}$ cells compared to stimulated PBMCs from adult subjects (22). In both these studies, reduced priming by DCs was believed to be one of the factors for the observed decreased activation of T cells, though direct priming of $\mathrm{T}$ cells by DC was not performed. In addition to MoDCs, we also observed a reduction in the capacity of pDCs from elderly to prime CD4 and CD8 $\mathrm{T}$ cell responses after stimulation with influenza (31). Altogether, these studies suggest that DCs from elderly display a deficiency in priming naïve $\mathrm{T}$ cell responses after stimulation. Preexisting inflammation in aged subjects could be one of the possible mechanisms, which modifies DC responses and reduces their capacity to prime $\mathrm{T}$ cells. This is supported by a recent clinical trial using an mTOR inhibitor, RAD001, which reduces inflammation. Treatment of older subjects with RAD001 prior to influenza vaccination was demonstrated to decrease the percentage of PD-1-positive CD4 and CD8 T cells compared to placebo and enhance the response to influenza vaccination (53). Enhanced basal level activation was also demonstrated to be responsible for the reduced response to yellow fever vaccine of African subjects compared to European subjects (54). Strategies to reduce inflammation prior to vaccination may therefore prove useful in enhancing vaccine responses in the elderly.

Emerging evidence indicates that different subsets of DCs may display differential ability to prime CD4 and CD8 $\mathrm{T}$ cell responses. For example, CD1c DC subset is believed to express high levels of molecules such as Ifi30 (GILT), HLA-DMA, and cathepsin $\mathrm{H}$, which renders them more efficient in priming CD4 T lymphocyte responses (55). On the other hand, CD141 ${ }^{+}$ $\mathrm{mDC}$ subset possesses a superior capacity to cross-present antigens to CD8 T lymphocytes $(56,57)$. We have observed reduced percentages of $\mathrm{CD} 141^{+} \mathrm{mDC}$ subset in the circulation of the elderly, but the alterations in DC subsets in tissues have not been studied (23). In this regard, a recent study by Yu et al. (58) has used a human $\mathrm{CD}^{+} 4^{+}$hematopoietic progenitor cells reconstituted immunodeficient mice model to examine the $\mathrm{CD} 8^{+}$ $\mathrm{T}$ cell priming capacity of human respiratory CD1c $\mathrm{c}^{+}$and $\mathrm{CD} 141^{+}$ DCs against intranasal live-attenuated influenza virus vaccination. Their results indicate that both DC subsets were efficient at activating antiviral $\mathrm{CD}^{+} \mathrm{T}$ cell responses against influenza. Nevertheless, lung CD1c $\mathrm{c}^{+}$DCs induced the expression of CD103 on the CD8 T cells, which allowed their retention in the lung epithelium and generate tissue-resident memory cells. Antigenpresenting capacity of different DC subsets in the elderly thus needs to be examined not only because of their capacity to prime different $\mathrm{T}$ lymphocyte subset but also since emerging evidence indicates different vaccines activate different DC subsets, and this differential activation is required for efficient adaptive immune responses (59). Fluzone was demonstrated to primarily activate MoDCs, while pneumovax activated monocytes. In contrast, Gardasil induced the activation of CD1c ${ }^{+}$blood DCs (59). The specialization of APCs in response to different vaccines will have to be kept in mind when designing vaccines for the elderly. The response of different DC subsets to vaccine antigens and adjuvants may be determined to obtain information about the induction of adaptive immunity. For example, to improve vaccine response to fluzone in the elderly, it may be beneficial to design adjuvants that activate monocytes. In addition to the above parameters, the strength and duration of antigen priming by DCs also affects memory generation. A recent murine study with vaccinia virus demonstrated that cross presentation of antigens by DCs to TCR-identical cells leads to generation of tissue-resident memory $\mathrm{CD}^{+} \mathrm{T}$ cells versus the circulating memory cells (60). Studies examining the generation of tissue-resident memory in human subjects are not feasible due to ethical considerations. However, use of reconstituted humanized mice as described above (58) may be one of the approaches to examine tissue-specific human responses. Another approach is the emerging field of systems vaccinology (61), which may provide insight into the transcriptional and epigenetic signatures that could be predictive of reduced vaccine responsiveness in the elderly and may help design strategies to overcome the deficiencies.

\section{DCs AND DAMAGE-ASSOCIATED MOLECULAR PATTERNS (DAMPS)}

In contrast to exogenous danger threats, there is not much known about the response of DCs from aged subjects to endogenous, DAMPs. DAMPs are released upon cell or tissue damage, and enhanced tissue damage is a characteristic of aging. The inflammasome pathway plays a major role in recognizing a wide array of DAMPS including cholesterol crystals, uric acid crystals, extracellular ATP, amyloid-beta, and ceramides and lipids (62, 63), many of these molecules accumulate during aging (64). Studies in mice have linked impaired glucose tolerance and cognitive decline to enhanced expression of NLRP3 inflammasome pathway during aging (65). The increased TNF- $\alpha$ levels in aged mice were reported to enhance the expression of NLRP3 inflammasome in adipose tissue and liver, which results in impaired glucose tolerance. A recent study (66) in humans has demonstrated a direct correlation between specific inflammasome expression 
modules and age-related diseases such as hypertension, as well as with diminished longevity. The study identified two metabolites, adenine and $N^{4}$-acetylcytidine, which prime and/or activate the NLRC4 inflammasome and induce hypertension and inflammatory signatures. These studies indicate an enhanced activity of the inflammasome pathway during aging; however, these changes have not been determined in DCs. Aging also leads to changes/ loss in protein homeostasis, proteostasis due to intracellular damage, which contributes to the pathogenesis of neurodegenerative diseases such as Alzheimer's disease (67). It would be interesting to determine the response of DCs from healthy aged subjects to some of the pathological proteins such as amyloid-beta and compare it to response of DCs from AD patients.

\section{DCs AND TOLERANCE}

Maintenance of tolerance against self-antigens is another primary function of DCs (68). DCs are constantly being exposed to selfantigens generated during cell death, tissue injury, etc. Under steady-state conditions, DCs in the periphery uptake these antigens but do not get activated. Presentation of self-antigens to $\mathrm{T}$ cells in the absence of costimulatory molecules or activation signals leads to T cell tolerance via T cell anergy or induction of $\mathrm{T}$ regulatory cells. However, if the environment is inflamed and the DCs are activated, they may present self-antigens to T cells to generate an immune response against self-antigens. This can lead to autoimmunity and inflammation. Since our group and others $(18,69)$ have observed that DCs from aged subjects secrete low basal levels of pro-inflammatory cytokines, it is suggested that the DCs are activated. Indeed, we observed increased basal level of NF- $\kappa \mathrm{B}$ activation in DCs from aged subjects (70). Furthermore, we also found increased reactivity of DCs from aged subjects to self-DNA. Self-DNA is released when apoptotic cells' clearance is defective and cells undergo secondary necrosis. In keeping with this, DCs from aged subjects exhibited reduced uptake of apoptotic cells (70). The increased immune response instead of tolerance to self-antigens contributes to the inflammation during aging (Figure 1).

In addition to peripheral tolerance, DCs also play a role in maintaining tolerance at mucosal surfaces (71). The lung and gut mucosa are constantly exposed to harmless and innocuous antigens in the form of particles from inhaled air and food. Furthermore, the commensal microbial communities present in the oral and gastrointestinal mucosa are essential for human health and thus an immune response against them would be detrimental. Significant progress has been made in the last few years identifying DCs as critical mediators of tolerance induction at these surfaces. The epithelial cells in the mucosa secrete factors such as retinoic acid and TGF- $\beta$, which act upon DCs to induce tolerance to prevent response against harmless antigens and commensal microbiome (71-73). Our studies suggest that DCs from aged subjects display impaired response to retinoic acid and are deficient in inducing $\mathrm{T}$ regulatory cells for tolerance (23). The infections of the respiratory mucosa such as the influenza and Chlamydia pneumoniae are more prevalent and severe in the elderly (74). The older population is also more susceptible to bronchitis, asthma, COPD, and emphysema
(74-76). Reduced capacity of DCs from aged subjects to maintain tolerance in the airways may enhance inflammation and invasion by pathogens due to impaired remodeling of the airways. Furthermore, we have also demonstrated that the basal level of activation of DCs from aged subjects leads to low-level secretion of pro-inflammatory cytokines, which activates the epithelium even in the absence of infection (69). Exposure of airway epithelial cells to supernatants from unstimulated DCs from aged subjects, but not young subjects, led to an increase in permeability of the epithelial barrier, which was accompanied with secretion of chemokines and upregulation of activation molecules. Therefore, DCs from aged subjects are not only defective in their response to tolerogenic signals from epithelial cells but also act on the epithelium to compromise its barrier functions.

Although studies were performed with airway epithelial cells and DCs, a similar process may be occurring at the level of gut and skin. Infections of both these surfaces are also more common in the elderly (77). For example, Helicobacter pylori and Clostridium difficile infections of the gut are often more severe and result in hospitalization of the elderly (78). It is also well established that with advancing age there are significant changes in the composition of gut microbiota with increase in Gramnegative bacteria, like Enterobacteriaceae and other pathogens (79). These Gram-negative bacteria secrete lipopolysaccharides, and we have previously reported that inflammatory response to LPS is enhanced with age (21). In addition, the level of shortchain fatty acids (SCFAs), such as acetate, butyrate, and propionate, are also reduced in the intestine of aged subjects as compared to young subjects (80). SCFAs synthesized by gut microbiota can act on DCs to prevent their activation and enhance their capacity to induce $\mathrm{T}$ regulatory cells to maintain tolerance in the gut (81). Enhanced inflammation in the gut increases the susceptibility of the elderly to gastrointestinal infections. Similar to gut infections of the skin including viral infections like herpes zoster (shingles), pressure ulcers, bacterial, or fungal infections, methicillin-resistant Staphylococcus aureus are prevalent in the elderly. Aberrant functions of DCs at the mucosal surfaces may account for the increased mucosal infections observed in the elderly.

\section{POTENTIAL MECHANISMS RESPONSIBLE FOR DC DYSFUNCTION IN THE ELDERLY}

The above studies highlight the age-associated alterations in DC functions; however, the mechanisms responsible for the changes are not well understood. Changes in signaling mechanisms such as enhanced basal level activation of NF- $\mathrm{KB}$ are thought to be responsible for the increased inflammatory responses of the DCs from the elderly. This has been observed both in MoDCs and circulatory DCs $(18,21,70)$. Nevertheless, it is still not defined whether the changes are due to an intrinsic defect in DCs or external senescent microenvironment drives the changes. Evidence regarding both mechanisms is present. The age-associated increased circulatory pro-inflammatory mediators such as TNF- $\alpha$, prostaglandins can cause DCs to mature and 
secrete pro-inflammatory cytokines at homeostasis. This process can start during DC differentiation in the bone marrow since the fat content in bone marrow has been shown to increase with age (82), and adipocytes are major producers of pro-inflammatory cytokines (83). DC intrinsic mechanisms such as epigenetic changes including chromatin and methylation alterations or changes in micro RNA may also account for observed changes in DC function. We have observed increased binding of type I and type III IFN promoters to inhibitory histone, H3K9 (36), but studies comparing the chromatin accessible elements at a global level have not been performed in DCs from aged and young subjects. The inability to obtain sufficient number of DCs from the blood of the elderly has been a major hindrance. The advent of novel next generation techniques such as ATAC-seq (84) as well as single-cell sequencing (85) may enhance the feasibility of performing such studies. Similarly, changes in DNA methylation in $\mathrm{T}$ lymphocytes have been well documented in aging (86). However, methylation changes in DCs have not been studied in aged subjects. This is an area of importance for future studies as methylation has a significant impact on gene function (87). Studies focused on age-associated alterations in the expression of long non-coding RNAs (88) are also of potential importance to understand the mechanisms underlying DC dysfunction in the elderly.

\section{REFERENCES}

1. Passarino G, De Rango F, Montesanto A. Human longevity: genetics or lifestyle? It takes two to tango. Immun Ageing (2016) 13:12. doi:10.1186/s12979-016-0066-Z

2. Carmona JJ, Michan S. Biology of healthy aging and longevity. Rev Invest Clin (2016) 68:7-16.

3. Yashin AI, Arbeev KG, Arbeeva LS, Wu D, Akushevich I, Kovtun M, et al. How the effects of aging and stresses of life are integrated in mortality rates: insights for genetic studies of human health and longevity. Biogerontology (2016) 17:89-107. doi:10.1007/s10522-015-9594-8

4. Monti D, Ostan R, Borelli V, Castellani G, Franceschi C. Inflammaging and human longevity in the omics era. Mech Ageing Dev (2016). doi:10.1016/j.mad.2016.12.008

5. Martinez de Toda I, Mate I, Vida C, Cruces J, De la Fuente M. Immune function parameters as markers of biological age and predictors of longevity. Aging (2016) 8:3110-9. doi:10.18632/aging.101116

6. Kim C, Fang F, Weyand CM, Goronzy JJ. The life cycle of a T cell after vaccination - where does immune ageing strike? Clin Exp Immunol (2017) 187:71-81. doi:10.1111/cei.12829

7. Agrawal A, Gupta S. Impact of aging on dendritic cell functions in humans. Ageing Res Rev (2011) 10:336-45. doi:10.1016/j.arr.2010.06.004

8. Banchereau J, Steinman RM. Dendritic cells and the control of immunity. Nature (1998) 392:245-52. doi:10.1038/32588

9. Steinman RM, Inaba K, Turley S, Pierre P, Mellman I. Antigen capture, processing, and presentation by dendritic cells: recent cell biological studies. Hum Immunol (1999) 60:562-7. doi:10.1016/S0198-8859(99)00030-0

10. Dudek AM, Martin S, Garg AD, Agostinis P. Immature, semi-mature, and fully mature dendritic cells: toward a DC-cancer cells interface that augments anticancer immunity. Front Immunol (2013) 4:438. doi:10.3389/fimmu.2013.00438

11. Iwasaki A, Medzhitov R. Regulation of adaptive immunity by the innate immune system. Science (2010) 327:291-5. doi:10.1126/science.1183021

12. Pulendran B, Maddur MS. Innate immune sensing and response to influenza. Curr Top Microbiol Immunol (2015) 386:23-71. doi:10.1007/82_2014_405

13. Bianchi ME. DAMPs, PAMPs and alarmins: all we need to know about danger. J Leukoc Biol (2007) 81:1-5. doi:10.1189/jlb.0306164

14. Kornete M, Piccirillo CA. Functional crosstalk between dendritic cells and Foxp3(+) regulatory $\mathrm{T}$ cells in the maintenance of immune tolerance. Front Immunol (2012) 3:165. doi:10.3389/fimmu.2012.00165

\section{CONCLUSION}

In summary, aging impacts DC functions in multiple ways. The enhanced activated state of DCs from elderly leads to the erosion of peripheral and mucosal tolerance and induction of inflammation. The secretion of inflammatory cytokines by activated DCs is also uncontrolled due to a defect in IL-10 secretion. In addition, the secretion of type I and III interferons is compromised, which enhances the susceptibility of the elderly to viral and bacterial infections. More studies are required to understand the effect of age on various DC subsets particularly in the tissues.

\section{AUTHOR CONTRIBUTIONS}

AA wrote the review with the help of SA and SG.

\section{FUNDING}

The project described was supported by AG045216 to AA and National Center for Research Resources and the National Center for Advancing Translational Sciences, National Institutes of Health, through Grant UL1 TR000153. The content is solely the responsibility of the authors and does not necessarily represent the official views of the NIH.

15. Mildner A, Jung S. Development and function of dendritic cell subsets. Immunity (2014) 40:642-56. doi:10.1016/j.immuni.2014.04.016

16. Tang Q, Koh LK, Jiang D, Schwarz H. CD137 ligand reverse signaling skews hematopoiesis towards myelopoiesis during aging. Aging (2013) 5:643-52. doi:10.18632/aging.100588

17. Wang J, Geiger H, Rudolph KL. Immunoaging induced by hematopoietic stem cell aging. Curr Opin Immunol (2011) 23:532-6. doi:10.1016/j.coi.2011.05.004

18. Panda A, Qian F, Mohanty S, van Duin D, Newman FK, Zhang L, et al. Ageassociated decrease in TLR function in primary human dendritic cells predicts influenza vaccine response. J Immunol (2010) 184:2518-27. doi:10.4049/ jimmunol.0901022

19. Garbe K, Bratke K, Wagner S, Virchow JC, Lommatzsch M. Plasmacytoid dendritic cells and their toll-like receptor 9 expression selectively decrease with age. Hum Immunol (2012) 73:493-7. doi:10.1016/j.humimm.2012.02.007

20. Jing Y, Shaheen E, Drake RR, Chen N, Gravenstein S, Deng Y. Aging is associated with a numerical and functional decline in plasmacytoid dendritic cells, whereas myeloid dendritic cells are relatively unaltered in human peripheral blood. Hum Immunol (2009) 70:777-84. doi:10.1016/j.humimm.2009.07.005

21. Agrawal A, Agrawal S, Cao JN, Su H, Osann K, Gupta S. Altered innate immune functioning of dendritic cells in elderly humans: a role of phosphoinositide 3-kinase-signaling pathway. J Immunol (2007) 178:6912-22. doi:10.4049/ jimmunol.178.11.6912

22. Metcalf TU, Cubas RA, Ghneim K, Cartwright MJ, Grevenynghe JV, Richner $\mathrm{JM}$, et al. Global analyses revealed age-related alterations in innate immune responses after stimulation of pathogen recognition receptors. Aging Cell (2015) 14:421-32. doi:10.1111/acel.12320

23. Agrawal S, Ganguly S, Tran A, Sundaram P, Agrawal A. Retinoic acid treated human dendritic cells induce $\mathrm{T}$ regulatory cells via the expression of CD141 and GARP which is impaired with age. Aging (2016) 8:1223-35. doi:10.18632/ aging. 100973

24. Lundberg K, Albrekt AS, Nelissen I, Santegoets S, de Gruijl TD, Gibbs S, et al. Transcriptional profiling of human dendritic cell populations and models - unique profiles of in vitro dendritic cells and implications on functionality and applicability. PLoS One (2013) 8:e52875. doi:10.1371/journal. pone. 0052875

25. Lung TL, Saurwein-Teissl M, Parson W, Schonitzer D, Grubeck-Loebenstein B. Unimpaired dendritic cells can be derived from monocytes in old age and can 
mobilize residual function in senescent T cells. Vaccine (2000) 18:1606-12. doi:10.1016/S0264-410X(99)00494-6

26. Steger MM, Maczek C, Grubeck-Loebenstein B. Morphologically and functionally intact dendritic cells can be derived from the peripheral blood of aged individuals. Clin Exp Immunol (1996) 105:544-50. doi:10.1046/j. 1365-2249.1996.d01-790.x

27. Cao AA, Jia Z, Sherman E, Gupta S. Alterations in gene array patterns in dendritic cells from aged humans. PLoS One (2014) 9(9):e106471. doi:10.1371/ journal.pone. 0106471

28. Granot T, Senda T, Carpenter DJ, Matsuoka N, Weiner J, Gordon CL, et al. Dendritic cells display subset and tissue-specific maturation dynamics over human life. Immunity (2017) 46:504-15. doi:10.1016/j. immuni.2017.02.019

29. Yoshikawa TT. Epidemiology and unique aspects of aging and infectious diseases. Clin Infect Dis (2000) 30:931-3. doi:10.1086/313792

30. Swiecki M, Colonna M. The multifaceted biology of plasmacytoid dendritic cells. Nat Rev Immunol (2015) 15:471-85. doi:10.1038/nri3865

31. Sridharan A, Esposo M, Kaushal K, Tay J, Osann K, Agrawal S, et al. Ageassociated impaired plasmacytoid dendritic cell functions lead to decreased CD4 and CD8 T cell immunity. Age (2011) 33:363-76. doi:10.1007/ s11357-010-9191-3

32. Qian F, Wang X, Zhang L, Lin A, Zhao H, Fikrig E, et al. Impaired interferon signaling in dendritic cells from older donors infected in vitro with West Nile virus. J Infect Dis (2011) 203:1415-24. doi:10.1093/infdis/jir048

33. Della Bella S, Bierti L, Presicce P, Arienti R, Valenti M, Saresella M, et al. Peripheral blood dendritic cells and monocytes are differently regulated in the elderly. Clin Immunol (2007) 122:220-8. doi:10.1016/j.clim.2006.09.012

34. Prakash S, Agrawal S, Ma D, Gupta S, Peterson EM, Agrawal A. Dendritic cells from aged subjects display enhanced inflammatory responses to Chlamydophila pneumoniae. Mediators Inflamm (2014) 2014:436438. doi: $10.1155 / 2014 / 436438$

35. Agrawal S, Gollapudi S, Gupta S, Agrawal A. Dendritic cells from the elderly display an intrinsic defect in the production of IL-10 in response to lithium chloride. Exp Gerontol (2013) 48:1285-92. doi:10.1016/j.exger.2013.08.006

36. Prakash S, Agrawal S, Cao JN, Gupta S, Agrawal A. Impaired secretion of interferons by dendritic cells from aged subjects to influenza: role of histone modifications. Age (2013) 35:1785-97. doi:10.1007/s11357-012-9477-8

37. Contoli M, Message SD, Laza-Stanca V, Edwards MR, Wark PA, Bartlett NW, et al. Role of deficient type III interferon-lambda production in asthma exacerbations. Nat Med (2006) 12:1023-6. doi:10.1038/nm1462

38. Mordstein M, Neugebauer E, Ditt V, Jessen B, Rieger T, Falcone V, et al. Lambda interferon renders epithelial cells of the respiratory and gastrointestinal tracts resistant to viral infections. J Virol (2010) 84:5670-7. doi:10.1128/ JVI.00272-10

39. Dorrington MG, Bowdish DM. Immunosenescence and novel vaccination strategies for the elderly. Front Immunol (2013) 4:171. doi:10.3389/ fimmu.2013.00171

40. Weinberger B, Grubeck-Loebenstein B. Vaccines for the elderly. Clin Microbiol Infect (2012) 18(Suppl 5):100-8. doi:10.1111/j.1469-0691.2012.03944.x

41. Nikolich-Zugich J. Aging of the $\mathrm{T}$ cell compartment in mice and humans: from no naive expectations to foggy memories. J Immunol (2014) 193:2622-9. doi:10.4049/jimmunol.1401174

42. Sallusto F, Lanzavecchia A. The instructive role of dendritic cells on T-cell responses. Arthritis Res (2002) 4(Suppl 3):S127-32. doi:10.1186/ar567

43. Dolfi DV, Duttagupta PA, Boesteanu AC, Mueller YM, Oliai CH, Borowski AB, et al. Dendritic cells and CD28 costimulation are required to sustain virusspecific CD8+ T cell responses during the effector phase in vivo. J Immunol (2011) 186:4599-608. doi:10.4049/jimmunol.1001972

44. Fuse S, Zhang W, Usherwood EJ. Control of memory CD8+ T cell differentiation by CD80/CD86-CD28 costimulation and restoration by IL-2 during the recall response. JImmunol (2008) 180:1148-57. doi:10.4049/ jimmunol.180.2.1148

45. McGill J, Van Rooijen N, Legge KL. Protective influenza-specific CD8 T cell responses require interactions with dendritic cells in the lungs. J Exp Med (2008) 205:1635-46. doi:10.1084/jem.20080314

46. Teijaro JR, Njau MN, Verhoeven D, Chandran S, Nadler SG, Hasday J, et al. Costimulation modulation uncouples protection from immunopathology in memory T cell responses to influenza virus. J Immunol (2009) 182:6834-43. doi:10.4049/jimmunol.0803860
47. Borowski AB, Boesteanu AC, Mueller YM, Carafides C, Topham DJ, Altman JD, et al. Memory CD8+ T cells require CD28 costimulation. J Immunol (2007) 179:6494-503. doi:10.4049/jimmunol.179.10.6494

48. Moretto MM, Lawlor EM, Khan IA. Aging mice exhibit a functional defect in mucosal dendritic cell response against an intracellular pathogen. J Immunol (2008) 181:7977-84. doi:10.4049/jimmunol.181.11.7977

49. Li G, Smithey MJ, Rudd BD, Nikolich-Zugich J. Age-associated alterations in CD8alpha+ dendritic cells impair CD8 T-cell expansion in response to an intracellular bacterium. Aging Cell (2012) 11:968-77. doi:10.1111/j.1474-9726.2012.00867.x

50. Paula C, Motta A, Schmitz C, Nunes CP, Souza AP, Bonorino C. Alterations in dendritic cell function in aged mice: potential implications for immunotherapy design. Biogerontology (2009) 10:13-25. doi:10.1007/s10522-008-9150-х

51. Looney RJ, Falsey AR, Walsh E, Campbell D. Effect of aging on cytokine production in response to respiratory syncytial virus infection. J Infect Dis (2002) 185:682-5. doi:10.1086/339008

52. Briceno O, Lissina A, Wanke K, Afonso G, von Braun A, Ragon K, et al. Reduced naive CD8(+) T-cell priming efficacy in elderly adults. Aging Cell (2016) 15:14-21. doi:10.1111/acel.12384

53. Mannick JB, Del Giudice G, Lattanzi M, Valiante NM, Praestgaard J, Huang B, et al. mTOR inhibition improves immune function in the elderly. Sci Transl Med (2014) 6:268ra179. doi:10.1126/scitranslmed.3009892

54. Muyanja E, Ssemaganda A, Ngauv P, Cubas R, Perrin H, Srinivasan D, et al. Immune activation alters cellular and humoral responses to yellow fever 17D vaccine. J Clin Invest (2014) 124:3147-58. doi:10.1172/JCI75429

55. Dudziak D, Kamphorst AO, Heidkamp GF, Buchholz VR, Trumpfheller C, Yamazaki S, et al. Differential antigen processing by dendritic cell subsets in vivo. Science (2007) 315:107-11. doi:10.1126/science.1136080

56. Jongbloed SL, Kassianos AJ, McDonald KJ, Clark GJ, Ju X, Angel CE, et al. Human CD141+ (BDCA-3)+ dendritic cells (DCs) represent a unique myeloid DC subset that cross-presents necrotic cell antigens. J Exp Med (2010) 207:1247-60. doi:10.1084/jem.20092140

57. Haniffa M, Shin A, Bigley V, McGovern N, Teo P, See P, et al. Ginhoux, human tissues contain CD141hi cross-presenting dendritic cells with functional homology to mouse CD103+ nonlymphoid dendritic cells. Immunity (2012) 37:60-73. doi:10.1016/j.immuni.2012.04.012

58. Yu CI, Becker C, Wang Y, Marches F, Helft J, Leboeuf M, et al. Human CD1c+ dendritic cells drive the differentiation of $\mathrm{CD} 103+\mathrm{CD} 8+$ mucosal effector $\mathrm{T}$ cells via the cytokine TGF-beta. Immunity (2013) 38:818-30. doi:10.1016/j. immuni.2013.03.004

59. Banchereau R, Baldwin N, Cepika AM, Athale S, Xue Y, Yu CI, et al. Transcriptional specialization of human dendritic cell subsets in response to microbial vaccines. Nat Commun (2014) 5:5283. doi:10.1038/ncomms6283

60. Iborra S, Martinez-Lopez M, Khouili SC, Enamorado M, Cueto FJ, Conde-Garrosa R, et al. Optimal generation of tissue-resident but not circulating memory $\mathrm{T}$ cells during viral infection requires crosspriming by DNGR-1+ dendritic cells. Immunity (2016) 45:847-60. doi:10.1016/j. immuni.2016.08.019

61. Nakaya HI, Hagan T, Duraisingham SS, Lee EK, Kwissa M, Rouphael N, et al. Systems analysis of immunity to influenza vaccination across multiple years and in diverse populations reveals shared molecular signatures. Immunity (2015) 43:1186-98. doi:10.1016/j.immuni.2015.11.012

62. Leemans JC, Cassel SL, Sutterwala FS. Sensing damage by the NLRP3 inflammasome. Immunol Rev (2011) 243:152-62. doi:10.1111/j.1600-065X. 2011.01043.x

63. Davis BK, Wen H, Ting JP. The inflammasome NLRs in immunity, inflammation, and associated diseases. Annu Rev Immunol (2011) 29:707-35. doi:10.1146/annurev-immunol-031210-101405

64. Kapetanovic R, Bokil NJ, Sweet MJ. Innate immune perturbations, accumulating DAMPs and inflammasome dysregulation: a ticking time bomb in ageing. Ageing Res Rev (2015) 24:40-53. doi:10.1016/j.arr.2015.02.005

65. Youm YH, Grant RW, McCabe LR, Albarado DC, Nguyen KY, Ravussin A, et al. Canonical Nlrp3 inflammasome links systemic low-grade inflammation to functional decline in aging. Cell Metab (2013) 18:519-32. doi:10.1016/j. cmet.2013.09.010

66. Furman D, Chang J, Lartigue L, Bolen CR, Haddad F, Gaudilliere B, et al. Expression of specific inflammasome gene modules stratifies older individuals into two extreme clinical and immunological states. Nat Med (2017) 23:174-84. doi:10.1038/nm.4267 
67. Kaushik S, Cuervo AM. Proteostasis and aging. Nat Med (2015) 21:1406-15. doi:10.1038/nm.4001

68. Steinman RM, Hawiger D, Liu K, Bonifaz L, Bonnyay D, Mahnke K, et al. Dendritic cell function in vivo during the steady state: a role in peripheral tolerance. Ann N Y Acad Sci (2003) 987:15-25. doi:10.1111/j.1749-6632.2003. tb06029.x

69. Prakash S, Agrawal S, Vahed H, Ngyuen M, Benmohamad L, Gupta S, et al. Dendritic cells from aged subjects contribute to chronic airway inflammation by activating bronchial epithelial cells under steady state. Mucosal Immunol (2014) 7:1386-94. doi:10.1038/mi.2014.28

70. Agrawal A, Tay J, Ton S, Agrawal S, Gupta S. Increased reactivity of dendritic cells from aged subjects to self-antigen, the human DNA. J Immunol (2009) 182:1138-45. doi:10.4049/jimmunol.182.2.1138

71. del Rio ML, Bernhardt G, Rodriguez-Barbosa JI, Forster R. Development and functional specialization of CD103+ dendritic cells. Immunol Rev (2010) 234:268-81. doi:10.1111/j.0105-2896.2009.00874.x

72. Bakdash G, Vogelpoel LT, van Capel TM, Kapsenberg ML, de Jong EC. Retinoic acid primes human dendritic cells to induce gut-homing, IL-10producing regulatory T cells. Mucosal Immunol (2015) 8:265-78. doi:10.1038/ mi.2014.64

73. Coombes JL, Siddiqui KR, Arancibia-Carcamo CV, Hall J, Sun CM, Belkaid Y, et al. A functionally specialized population of mucosal CD103+ DCs induces Foxp3+ regulatory $\mathrm{T}$ cells via a TGF-beta and retinoic acid-dependent mechanism. J Exp Med (2007) 204:1757-64. doi:10.1084/ jem. 20070590

74. Busse PJ, Mathur SK. Age-related changes in immune function: effect on airway inflammation. J Allergy Clin Immunol (2010) 126:690-9; quiz 700-1. doi:10.1016/j.jaci.2010.08.011

75. Burrows B, Barbee RA, Cline MG, Knudson RJ, Lebowitz MD. Characteristics of asthma among elderly adults in a sample of the general population. Chest (1991) 100:935-42. doi:10.1378/chest.100.4.935

76. Canan CH, Gokhale NS, Carruthers B, Lafuse WP, Schlesinger LS, Torrelles $\mathrm{JB}$, et al. Characterization of lung inflammation and its impact on macrophage function in aging. JLeukoc Biol (2014) 96:473-80. doi:10.1189/ jlb.4A0214-093RR

77. Mouton CP, Bazaldua OV, Pierce B, Espino DV. Common infections in older adults. Am Fam Physician (2001) 63:257-68.

78. Soenen S, Rayner CK, Jones KL, Horowitz M. The ageing gastrointestinal tract. Curr Opin Clin Nutr Metab Care (2016) 19:12-8. doi:10.1097/ MCO.0000000000000238
79. Kumar M, Babaei P, Ji B, Nielsen J. Human gut microbiota and healthy aging: recent developments and future prospective. Nutr Healthy Aging (2016) 4:3-16. doi:10.3233/NHA-150002

80. Biagi E, Nylund L, Candela M, Ostan R, Bucci L, Pini E, et al. Through ageing, and beyond: gut microbiota and inflammatory status in seniors and centenarians. PLoS One (2010) 5:e10667. doi:10.1371/journal.pone.0010667

81. Nastasi C, Candela M, Bonefeld CM, Geisler C, Hansen M, Krejsgaard T, et al. The effect of short-chain fatty acids on human monocyte-derived dendritic cells. Sci Rep (2015) 5:16148. doi:10.1038/srep16148

82. Tuljapurkar SR, McGuire TR, Brusnahan SK, Jackson JD, Garvin KL, Kessinger MA, et al. Changes in human bone marrow fat content associated with changes in hematopoietic stem cell numbers and cytokine levels with aging. J Anat (2011) 219:574-81. doi:10.1111/j.1469-7580.2011.01423.x

83. Tilg H, Moschen AR. Adipocytokines: mediators linking adipose tissue, inflammation and immunity. Nat Rev Immunol (2006) 6:772-83. doi:10.1038/ nri1937

84. Buenrostro JD, Wu B, Chang HY, Greenleaf WJ. ATAC-seq: a method for assaying chromatin accessibility genome-wide. Curr Protoc Mol Biol (2015) 109:21.29.1-9. doi:10.1002/0471142727.mb2129s109

85. Wu AR, Neff NF, Kalisky T, Dalerba P, Treutlein B, Rothenberg ME, et al. Quantitative assessment of single-cell RNA-sequencing methods. Nat Methods (2014) 11:41-6. doi:10.1038/nmeth.2694

86. Tserel L, Kolde R, Limbach M, Tretyakov K, Kasela S, Kisand K, et al. Agerelated profiling of DNA methylation in CD8+ T cells reveals changes in immune response and transcriptional regulator genes. Sci Rep (2015) 5:13107. doi:10.1038/srep13107

87. Han S, Brunet A. Histone methylation makes its mark on longevity. Trends Cell Biol (2012) 22:42-9. doi:10.1016/j.tcb.2011.11.001

88. Rinn JL, Chang HY. Genome regulation by long noncoding RNAs. Annu Rev Biochem (2012) 81:145-66. doi:10.1146/annurev-biochem-051410-092902

Conflict of Interest Statement: The authors declare that the research was conducted in the absence of any commercial or financial relationships that could be construed as a potential conflict of interest.

Copyright (c) 2017 Agrawal, Agrawal and Gupta. This is an open-access article distributed under the terms of the Creative Commons Attribution License (CC BY). The use, distribution or reproduction in other forums is permitted, provided the original author(s) or licensor are credited and that the original publication in this journal is cited, in accordance with accepted academic practice. No use, distribution or reproduction is permitted which does not comply with these terms. 